\title{
Cystic duct remnant stone removal by endoscopic retrograde cholangiopancreatography
}

\author{
Yogesh Harwani, Mahesh Goenka ${ }^{1}$, Vijay Rai ${ }^{1}$, Usha Goenka ${ }^{2}$ \\ Noble Institute of Gastroenterology, Ahmedabad, Gujarat, Departments of ${ }^{1}$ Gastroenterology and ${ }^{2}$ Interventional Radiology, \\ Apollo Gleneagles Hospital, Kolkata, West Bengal, India
}

$\begin{array}{ll}\text { Abstract } & \begin{array}{l}\text { Cystic duct remnant calculus (CDRC) is an important cause of postcholecystectomy } \\ \text { syndrome. }{ }^{[1]} \text { Open assess cholecystectomy or laparoscopic cholecystectomy of the remnant } \\ \text { duct is effective and considered to be preferred treatment. We report a case of } 65 \text {-year-old } \\ \text { female patient, a poor surgical candidate with CDRC who presented to us with biliary pain } \\ \text { and obstructive jaundice secondary to common bile duct (CBD) stones, in whom CDRC was } \\ \text { extracted during CBD clearance by endoscopic retrograde cholangiopancreatography. }\end{array} \\ \text { Key words } & \text { Cystic duct, endoscopic retrograde cholangiopancreatography }\end{array}$

\section{Introduction}

CDRC often leads to post cholecystectomy syndrome, though surgical modality of treatment is preferred choice, ERCP should be considered as an alternative choice for surgically unfit patient.

\section{Case Report}

A 65-year-old female with ischemic heart disease (IHD) and history of cholecystectomy 2 years back presented to us with intermittent biliary pain and obstructive jaundice for 3 weeks. Her significant laboratory parameters were as follows: Total bilirubin: $20 \mathrm{mg} / \mathrm{dl}$; direct bilirubin: $15 \mathrm{mg} / \mathrm{dl}$; alkaline phosphatase: $1238 \mathrm{IU}$; total leukocyte count: $23,500 / \mathrm{mm}^{3}$. Transabdominal ultrasound was suggestive of intrahepatic biliary radicle dilatation and dilated common bile duct (CBD) measuring $15 \mathrm{~mm}$ with three large calculi, largest measuring $12 \mathrm{~mm}$. Considering cholangitis, endoscopic retrograde

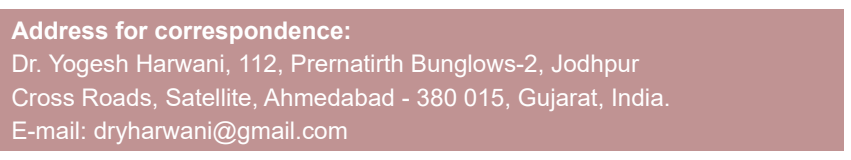

\begin{tabular}{|l|c|}
\hline \multicolumn{2}{|c|}{ Access this article online } \\
\hline \multirow{2}{*}{ Website: } & Quick Response Code \\
\hline www.jdeonline.in & \\
\hline DOI: & \\
10.4103/0976-5042.189153 & \\
\hline
\end{tabular}

cholangiopancreatography (ERCP) was performed, and CBD was selectively cannulated by sphincterotome (COOK endoscopy) [Figure 1]. On contrast three filling defects were noted in CBD suggestive of calculi, a cystic duct calculi approximately $8 \mathrm{~mm}$ was also noted in cystic duct remnant [Figure 3]. Sphincterotomy followed by controlled radial expansion balloon dilatation was performed for $1 \mathrm{~min}$ up to $15 \mathrm{~mm}$, and three large CBD calculi were removed by extractor balloon [Figure 2]. In view of CDRC, dilated cystic duct, and poor surgical candidature of patient, removal of CDRC by ERCP was attempted. Viziglide 0.035 wire (Olympus) was used for selective insertion of guide wire into cystic duct and with repeated attempts cystic duct could be cannulated, we inflated extractor balloon by $3 \mathrm{ml}$ room air proximal to cystic duct calculi and stone was removed [Figure 4]. Successful attempt to remove CDRC avoided repeat surgery in this poor surgical candidate patient.

\section{Discussion}

Cystic duct or gallbladder remnant with or without stones is one of the important causes of postcholecystectomy

This is an open access article distributed under the terms of the Creative Commons Attribution-NonCommercial-ShareAlike 3.0 License, which allows others to remix, tweak, and build upon the work non-commercially, as long as the author is credited and the new creations are licensed under the identical terms.

For reprints contact: reprints@medknow.com

How to cite this article: Harwani Y, Goenka M, Rai V, Goenka U. Cystic duct remnant stone removal by endoscopic retrograde cholangiopancreatography. J Dig Endosc 2016;7:65-7. 


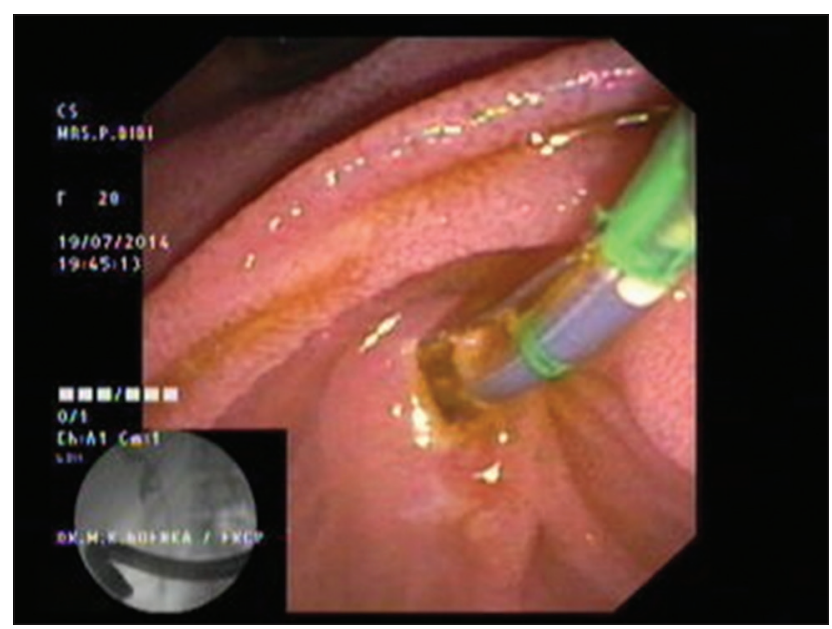

Figure 1: Cannulation of common bile duct

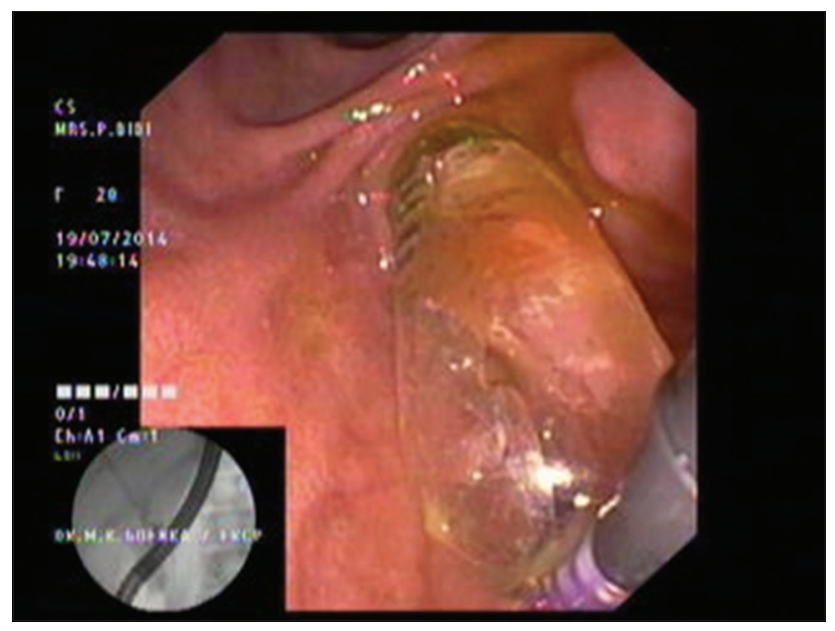

Figure 3: Controlled radial expansion of papilla

syndrome (PCS) as subtotal cholecystectomy procedures are increasing in the era of minimally invasive surgery. ${ }^{[2,3]}$ Incidence of PCS due to CDRC is $16 \%{ }^{[4]}$ Cystic duct more than or equal to $1 \mathrm{~cm}$ after surgery is considered to be cystic duct remnant, ${ }^{[5]}$ recommended ideal length of cystic duct stump is less the $5 \mathrm{~mm}$ after surgery. ${ }^{[6]}$ Cystic duct remnant can lead to recurrent cholelithiaisis, choledocholithiasis and recurrent cholangitis, mucocele, Mirizzi syndrome, and carcinoma. ${ }^{[7,8]}$ Open, laparoscopic or minimal invasive surgery depending on available expertise is recommended for CDRC. In patients with high risk for surgery other procedures such as ERCP, extra corporeal lithotripsy, cholangioscopy and percutaneous Fogarty balloon catheter deployment and stone removal are available options. In our case, patient was elderly and had IHD with ejection fraction $<35 \%$. ERCP and CDRC removal by extractor balloon prevented high-risk surgery in this case. Though ERCP is useful modality in such situation, cystic duct remnant has high potential for forming recurrent stones and may also develop malignancy; success depends on anatomical factors such as diameter of stone, diameter of cystic duct, and number of valves present in duct. Hence,

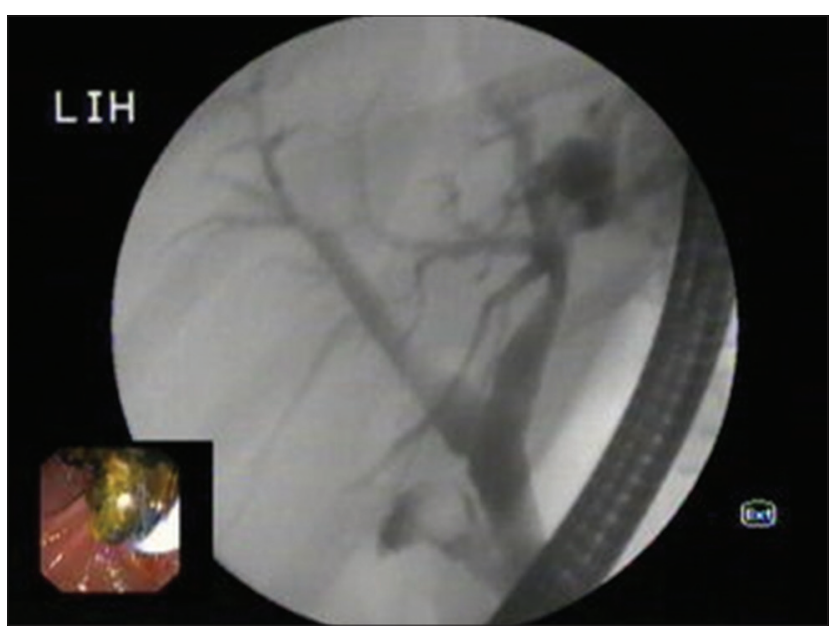

Figure 2: Cholangiogram showing cystic duct remnant calculi

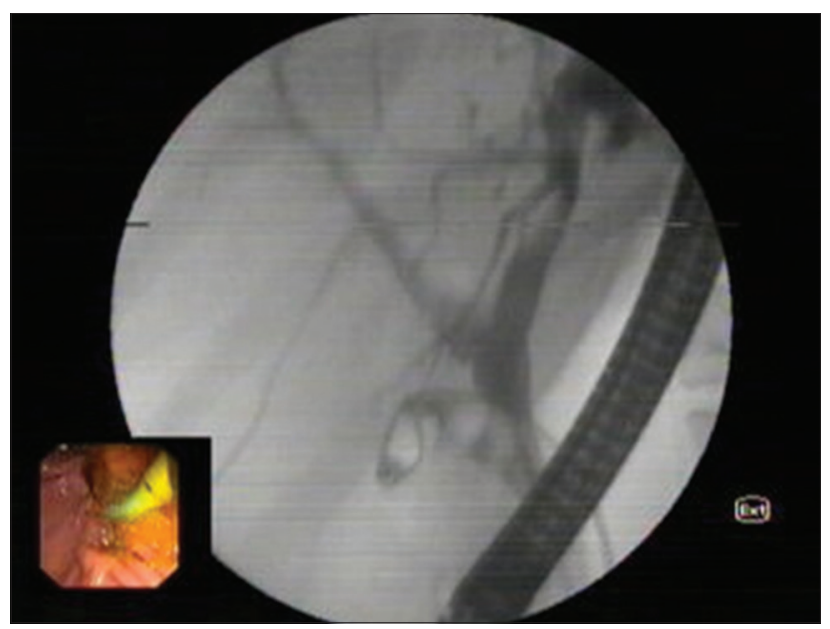

Figure 4: Balloon inflation and removal of cystic duct remnant calculi

we recommend such alternative therapy for patients who are unfit for surgery.

\section{Conclusion}

CDRC is an important cause of PCS. Although surgery is preferred treatment, other modalities of treatments especially ERCP in expert hands should be preferred over surgery in patients who are poor surgical candidates.

\section{Financial support and sponsorship} Nil.

\section{Conflicts of interest}

There are no conflicts of interest.

\section{References}

1. Palanivelu C, Rangarajan M, Jategaonkar PA, Madankumar MV, Anand NV. Laparoscopic management of remnant cystic duct calculi: A retrospective study. Ann R Coll Surg Engl 2009;91:25-9. 
2. Lum YW, House MG, Hayanga AJ, Schweitzer M. Postcholecystectomy syndrome in the laparoscopic era. J Laparoendosc Adv Surg Tech A 2006;16:482-5.

3. Chow M, von Waldenfels A, Pace R. An unusual case of a retained stone following laparoscopic cholecystectomy. J Laparoendosc Surg 1993;3:513-8.

4. Rozsos I, Magyaródi Z, Orbán P. Cystic duct syndrome and minimally invasive surgery. Orv Hetil 1997;138:2397-401.

5. Sitenko VM, Nechai AI, Stukalov VV, Kalashnikov SA. Large stump of the cystic duct. Vestn Khir Im I I Grek 1976;116:56-9.

6. Walsh RM, Ponsky JL, Dumot J. Retained gallbladder/cystic duct remnant calculi as a cause of postcholecystectomy pain. Surg Endosc 2002;16:981-4.

7. Enns R, Brown JA, Tiwari P, Amar J. Mirizzi's syndrome after cholecystectomy. Gastrointest Endosc 2001;53:629.

8. Bhuiya RM, Nimura Y, Kamiya J, Kondo S, Nagino M, Kanai M, et al. Recurrent carcinoma of cystic duct remnant with subcutaneous implantation in abdominal wall. HBP Surg 1997;4:223-6. 